\title{
The Grand Thaw: Our Vanishing Cryosphere
}

Rich Snow ${ }^{1 *}$ and Mary Snow ${ }^{1}$

${ }^{1}$ Professors of Meteorology, Embry-Riddle Aeronautical University, USA

${ }^{*}$ Corresponding author: Rich Snow, Professors of Meteorology, Embry-Riddle Aeronautical University, USA, Tel: 386-226-7104; E-mail: snow4fc@erau.edu

Rec date: May 29, 2014; Acc date: Jun 02, 2014; Pub date: Jun 09, 2014

Citation: Snow R, Snow M (2014) The Grand Thaw: Our Vanishing Cryosphere. J Climatol Weather Forecasting 2: e107. doi:10.4172/2332-2594.1000e107

Copyright: @ 2014 Snow R et al. This is an open-access article distributed under the terms of the Creative Commons Attribution License, which permits unrestricted use, distribution, and reproduction in any medium, provided the original author and source are credited.

\section{Editorial}

Records reveal that beginning in the 1950s there has been an accelerated reduction in ice and snow across most mountain glaciers and ice caps. The glaciers of the Tibetan Plateau and the Himalayan Mountains are the main source of water for the Ganges and the Indus Rivers. During the summer higher temperatures are causing these glaciers to melt at an increasing rate while during the winter the warmer temperature are yielding a dearth of snowfall, which in turn leads to drought. Along the equator in Africa, glaciers are faced with a similar same situation. In Uganda, 80 percent of the glaciers have disappeared since 1850 and by 2050 they are expected to be completely gone. Only 20 percent of the glaciers on Mount Kenya still remain today as the neighboring rivers continue to dry up, and even the majestic Snows of Mount Kilimanjaro are projected to vanish completely by the middle of the 21 st century. Since the 1900 s, the glaciers that grace the European Alps have lost 50 percent of their mass, and during the 2003 heat wave in which 30,000 Europeans died, a staggering seven feet of ice melted from the Alpine glaciers. Again in 2005, considered by the National Aeronautics and Space Administration (NASA) to be the warmest year on record, glacial melt water runoff caused extensive flooding across Switzerland. Even in Glacier National Park most of the glaciers are vanishing and the park is expected to be ice free within the next few decades.

The impact of global warming at the poles is more intense than elsewhere on the planet due to the extreme differences in radiation receipt during the winter and summer. Similarly, the additional heat at the poles has a much greater influence on normal temperatures than at the tropics which are already warm. Since the late 1950s, the extent of summer sea ice in the Arctic has decreased by about 40 percent losing nearly 2.5 million kilometers of ice in just the past 30 years. In 2007, the famous Northwest Passage theoretically connecting the Atlantic Ocean to the Pacific Ocean was declared ice free for a time, and it has been suggested that by 2030 there may be no summer sea ice in the Arctic. In fact, some models project that by the end of the century there may not be any sea ice even in winter.

Wintertime temperatures in Greenland over the past 15 years have risen some $5^{\circ}$ Celsius causing the Greenland Ice Sheet to shrink by 30 percent and lose approximately 200 cubic kilometers of ice each year. The rapid development of moulins along the periphery of the ice sheet allows more melt water to contact the rock base causing an increase of calving along the edges of the ice sheet. Among the fears of many researchers is the basil slippage of the Greenland Ice Sheet due to these emergent moulins, which could dramatically cause sea levels to rise if the ice sheet were to suddenly slide into the sea.

The world's largest ice sheets are in Antarctica and they too are swiftly melting. In West Antarctica between 1950 and 2000, the average annual temperature increased some $2.5^{\circ}$ Celsius; however, wintertime temperatures rose to $4.5^{\circ}$ Celsius above normal. The West Antarctic Ice Sheet is comprised of nearly 30,000 cubic kilometers of ice and is surrounded by ice shelves that serve as dams preventing the glaciers from slipping into the Southern Ocean. In 2000, a massive section of the Ross Ice Shelf so large it could be seen by satellite suddenly calved off, and later in 2002, a 3100 square kilometer chunk of the Larson B Ice Shelf broke free and drifted into the sea raising concerns that sea levels could rise as much as six meters if the West Antarctic Ice Sheet were to disintegrate.

In addition to the rapid melting of glaciers and ice sheets, much of the world's permafrost, which makes up 20 to 25 percent of the global landmass, is softening due to thawing. Since 1960, the temperature of the Siberian permafrost has risen by more than $1^{\circ}$ Celsius causing building foundations to crack and the forests of the taiga to lean drunkenly as the underlying soil liquefies. In the Alaskan tundra, the same type of damage is occurring accompanied by wildfires and the relentless northward migration of the bark beetle as the permafrost has warmed by nearly $3^{\circ}$ Celsius. Billions of tons of methane, which is 21 times more potent a greenhouse gas than carbon dioxide, are locked in the frozen permafrost. If these vast stores of methane are released, the negative impact on the atmosphere would be devastating.

Earth's temperature is predicted to increase from $2^{\circ}$ Celsius to as much as $6^{\circ}$ Celsius by the end of this century if the current rates of warming continue. Such temperature increases are unfathomable in that they have no equal in the past half million years and certainly have not been witnessed in the history of humankind. The unequivocal evidence for global warming is overwhelming and includes not only melting glaciers, sea ice, and permafrost, but also rising sea levels, higher storm surges, an increase in the acidity of the world's oceans, and greater frequencies of severe weather accompanied by more floods, droughts, and wild fires. The burning of fossil fuels and deforestation during the last 100 years has increased the level of carbon dioxide from 280 parts per million (ppm) to $396 \mathrm{ppm}$ in 2013 based on data from the Mauna Loa Observatory. Higher temperatures and rising carbon dioxide emissions are inextricably linked, and regardless of our actions, the atmosphere will continue to warm and glaciers will continue to retreat throughout the next century. Leaders from countries around the globe convene regularly seeking a resolution to this pressing problem, and as of yet have been unsuccessful in negotiating a binding agreement to reduce greenhouse gases. In each of their Special Reports on Emission Scenarios (SRES) the highly esteemed Intergovernmental Panel on Climate Change (IPCC) has repeatedly outlined the importance of the choices made by society in determining the degree to which the planet will continue to warm. The die is cast. Climate change is upon us. The boldness and efficiency with which individuals and governments act will make a substantial difference in the depth of the disasters that will ensue. 